\title{
Molt-dependent transcriptomic analysis of cement proteins in the barnacle Amphibalanus amphitrite
}

Zheng Wang ${ }^{1}$, Dagmar H. Leary ${ }^{1}$, Jinny Liu', Robert E. Settlage², Kenan P. Fears ${ }^{3}$, Stella H. North', Anahita Mostaghim ${ }^{1,4}$, Tara Essock-Burns ${ }^{3,5}$, Sarah E. Haynes ${ }^{3,6}$, Kathryn J. Wahl ${ }^{3}$ and Christopher M. Spillmann ${ }^{1 *}$

\begin{abstract}
Background: A complete understanding of barnacle adhesion remains elusive as the process occurs within and beneath the confines of a rigid calcified shell. Barnacle cement is mainly proteinaceous and several individual proteins have been identified in the hardened cement at the barnacle-substrate interface. Little is known about the molt- and tissue-specific expression of cement protein genes but could offer valuable insight into the complex multi-step processes of barnacle growth and adhesion.
\end{abstract}

Methods: The main body and sub-mantle tissue of the barnacle Amphibalanus amphitrite (basionym Balanus amphitrite) were collected in pre- and post-molt stages. RNA-seq technology was used to analyze the transcriptome for differential gene expression at these two stages and liquid chromatography-mass spectrometry/mass spectrometry (LC-MS/MS) was used to analyze the protein content of barnacle secretions.

Results: We report on the transcriptomic analysis of barnacle cement gland tissue in pre- and post-molt growth stages and proteomic investigation of barnacle secretions. While no significant difference was found in the expression of cement proteins genes at pre- and post-molting stages, expression levels were highly elevated in the sub-mantle tissue (where the cement glands are located) compared to the main barnacle body. We report the discovery of a novel $114 \mathrm{kD}$ cement protein, which is identified in material secreted onto various surfaces by adult barnacles and with the encoding gene highly expressed in the sub-mantle tissue. Further differential gene expression analysis of the sub-mantle tissue samples reveals a limited number of genes highly expressed in premolt samples with a range of functions including cuticular development, biominerialization, and proteolytic activity.

Conclusions: The expression of cement protein genes appears to remain constant through the molt cycle and is largely confined to the sub-mantle tissue. Our results reveal a novel and potentially prominent protein to the mix of cement-related components in A. amphitrite. Despite the lack of a complete genome, sample collection allowed for extended transcriptomic analysis of pre- and post-molt barnacle samples and identified a number of highly-expressed genes. Our results highlight the complexities of this sessile marine organism as it grows via molt cycles and increases the area over which it exhibits robust adhesion to its substrate.

Keywords: Cement protein, Molt cycle, Transcriptome, Proteome, Barnacle, Amphibalanus amphitrite

\footnotetext{
* Correspondence: christopher.spillmann@nrl.navy.mil

${ }^{1}$ Center for Bio/Molecular Science and Engineering, Naval Research Laboratory, Washington, DC 20375, USA

Full list of author information is available at the end of the article
} 


\section{Background}

Adhesion related to biological processes is often important to maintain proper function, and this is especially true of sessile marine organisms where substrate adhesion is critical for survival. A prominent example is the barnacle, which first relies on temporary adhesion on a suitable substrate as a cyprid and then transitions to permanent attachment as the animal undergoes metamorphosis to a sessile juvenile and matures to an adult with either a calcareous or membranous base attached to the underlying surface [1]. Barnacles are arthropods in the Crustacea subphylum and are partly characterized by their growth via molt cycles. Molting in adult acorn barnacles is evidenced by shedding of the exuvia as well as the formation of radial ecdysal lines underneath the animal. Much effort has been dedicated to understanding the intertwined processes of growth and adhesion as well as the composition and the molecular mechanisms that lead to a strongly adhered organism. These efforts are complicated by the presence of a rigid outer calcareous shell, under which cement components are delivered and deposited by the barnacle under the leading edge of the barnacle/substrate interface and sheltered from the external marine environment. As with growth, evidence suggests the process of adhesion occurs in a cyclic, multistep manner synchronized with the molt cycle $[2,3]$. The means by which cement precursor materials are delivered to the leading edge of the barnacle/substrate interface are not completely understood, yet a network of capillaries originating from cement glands and terminating at ducts at the substrate interface are thought to play a prominent role [2-4].

Barnacle cement itself is composed predominantly of protein [5-7], though other materials, such as lipids, polysaccharides and biomineralization components, have also been found at the barnacle-substrate interface [1]. Several putative cement proteins have been identified and studied, mainly through solubilization and analysis of cement plaques that remained on substrates following removal of the barnacle shell and body [7-12]. These include cp100k, cp68k, cp52k, cp20k, cp19k, where the number corresponds with the protein molecular weight in daltons. Detailed structural information about each protein remains unknown, though amino acid composition and conserved and/or repeat subunits have shed light on potential function $[9,12,13]$. Additionally, advances in gene sequencing technology have aided in the development of cDNA libraries as well as the discovery of genes that encode cement protein homologues in different barnacle species [14-16]. This knowledge continues to fill in the picture of how barnacles are able to create a robust adhesive interface in a relatively harsh marine environment.

With this backdrop, we set out to test the hypothesis that cement proteins are actively regulated at different stages of the molt cycle and in different tissues of adult barnacles. Molting of several adult Amphibalanus amphitrite (basionym Balanus amphitrite) barnacles was tracked based on shedding of the exuvia under controlled laboratory conditions. Protein and mRNA were collected from the sub-mantle tissue (containing the cement glands) of barnacles in pre- and post-molt stages. Material was also collected from the main body of adult barnacles for comparison. Using RNA-Seq technology, the expression levels of cement protein genes in the sub-mantle tissue of preand post-molt samples were found to be the same, suggesting these proteins are not regulated at the transcript level when synchronized to the molt cycle. Comparison of cement protein gene expression in the sub-mantle tissue versus the main barnacle body revealed significantly elevated levels in sub-mantle tissue. These results fit with the current understanding of barnacle anatomy, where cement pre-cursor material is thought to be produced and stored in cement glands located in the sub-mantle tissue. We also report the discovery of a novel $114 \mathrm{kD}$ protein, named Aacp114k, and found its transcript to be highly expressed in the sub-mantle tissue and the protein identified in barnacle cement secretions collected at the barnacle/substrate interface. This protein shares significant homology to a previously identified $100 \mathrm{kD}$ cement protein in A. amphitrite as well as others identified in the barnacle species Megabalanus rosa and Teraclita japonica formosana $[7,15,16]$.

In the absence of a complete genome, the information collected from the comparison of pre- and post-molt samples allowed for a more general analysis of differential gene expression in these two stages. A number of genes were identified as being up-regulated in the sub-mantle tissue predominantly in pre-molt barnacle samples with a range of functions including cuticular development, biominerialization, and proteolytic activity. Collectively, these results add a novel and potentially prominent protein to the mix of cement-related components and further our understanding of the complex processes at play as barnacles grow via cyclic molting and extend their adhesive area to substrates.

\section{Results}

\section{Sample collection and molt stage confirmation}

To test our hypothesis that cement protein genes are differentially expressed during the molt cycle of barnacles and in separate regions of the body, stable laboratory conditions were established for barnacles. Adult $A$. amphitrite individually reattached on glass slides were maintained and monitored in an incubator providing control over several variables including temperature, humidity, salinity, and light/dark cycles to minimize stressful environmental variables. Barnacles exhibiting stable, regular molting were selected in either a pre-molt or post-molt 
stage and the cirri and sub-mantle tissue were collected for further analysis. A barnacle schematic showing the cirri, main body, and sub-mantle tissue is shown in Fig. 1.

Each barnacle used in this study had the cirri removed for microscopic determination of the molt cycle based on the analysis of Davis et al. [17]. They reported significant temporal variability of the molt stages, yet the most common stages observed in the current study were the pre-molt, proecdysis (stage $\mathrm{D}$ ) and the post- and interecdysis stages ( $\mathrm{B}$ and $\mathrm{C}$ ). Postecdysis stage $\mathrm{A}$ is a very short period of $\sim 4 \mathrm{~h}$ immediately following a molt and was not observed in this study. The most distinguishing feature of the cirri was the state of the setae, the finger-like projections used to capture food during cirral pumping. As shown in Fig. 2a-b, pre-molt samples (stage D) were readily identified by the formation of new setae within the existing ones and invaginations into the main tissue of the cirri. Post-molt samples were noted by the absence of these features and the setal matrix in an expanded state (Fig. 2c-d). Using these identifiable features, the molt stage of each barnacle sample was categorized as being either pre- or post-molt.

\section{RNA-seq transcriptome analysis}

To understand barnacle cement protein gene expression levels in pre- and post-molt growth stages, RNA-seq technology was used to compare transcriptomic profiles of pre- and post-molt barnacles, specifically examining the sub-mantle tissue containing cement gland tissue. We first provide a general summary of these results. Complementary DNA (cDNA) libraries were constructed from three independent samples of sub-mantle tissue collected in pre-molt or post-molt stages. Two additional cDNA libraries were made from two pooled main body samples as pilot experiments for a total of eight separate samples.

Paired-end sequencing technology (Illumina) was performed on each of the eight cDNA libraries. A total of $149,850,897$ trimmed high-quality reads giving approximately 13.4 Gbp total sequences were generated with an average trimmed read length of $90 \mathrm{bp}$. De novo assembly of the A. amphitrite transcriptome was performed from combined reads from all eight samples using the Trinity program $[18,19]$. The summary of transcriptome sequencing and assembly is shown in Table 1. A total of 114.23 Mbp transcriptome sequences were assembled into 163,929 overlapping sequence data reads (contigs) with an average length of $697 \mathrm{bp}$. A summary of the contig length distribution is presented in Additional file 1. The transcriptome was then annotated with the program Trinotate [18]. From these data, 160,266 transcripts were predicted. Only 37,378 transcripts (23.3\%) have annotated functions that were identified using the SwissProt protein database and 6975 are assigned with gene ontology (GO) terms in 51 functional groups. Abundance profiles of functional groups (Additional file 2) are very similar to those previously reported in A. amphitrite and T. j. formosana $[15,16]$.

\section{Cement protein gene expression: pre-molt versus post- molt}

There is strong evidence that cement proteins are required for permanent adhesion of barnacles to their substrate and

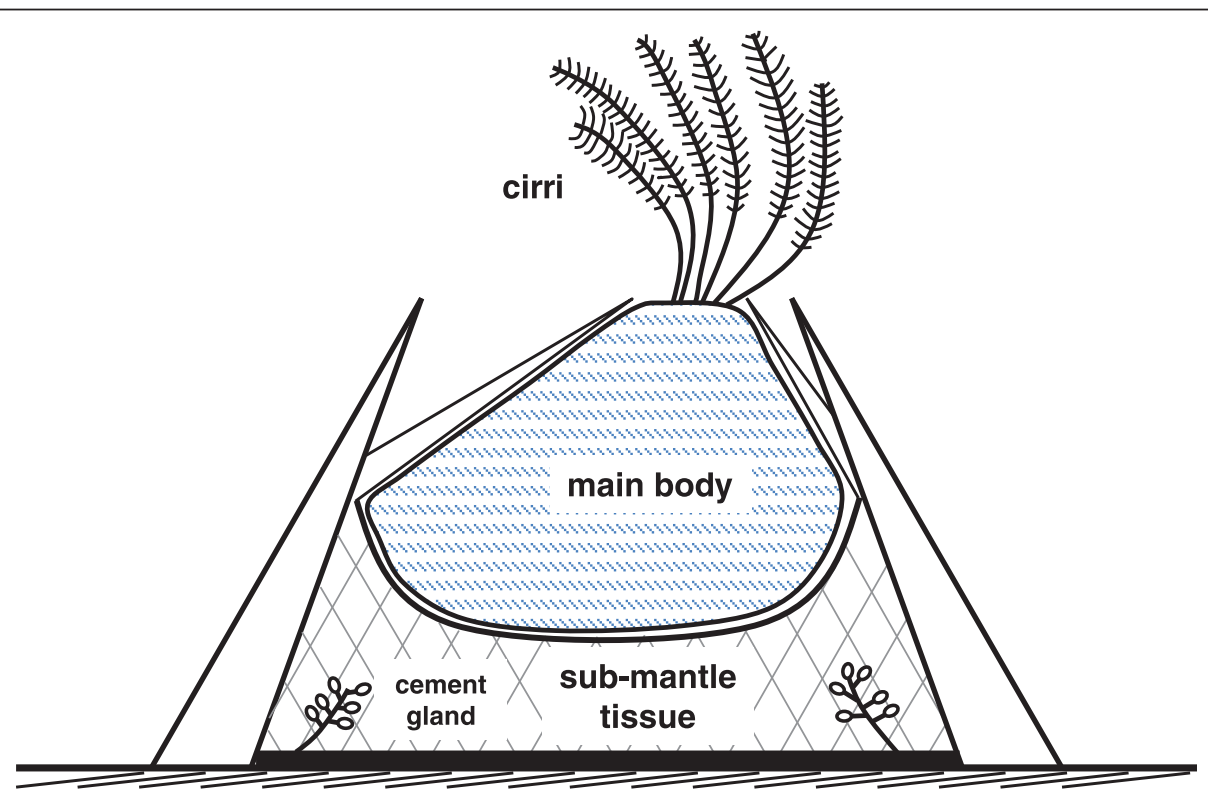

Fig. 1 Simplified schematic of adult acorn barnacle cross section. The three sections used in this study are shown. Cirri were used to confirm the molt stage of each sample, while the main body and sub-mantle tissue were collected for protein and mRNA analysis. Note the sub-mantle tissue contains the cement glands 

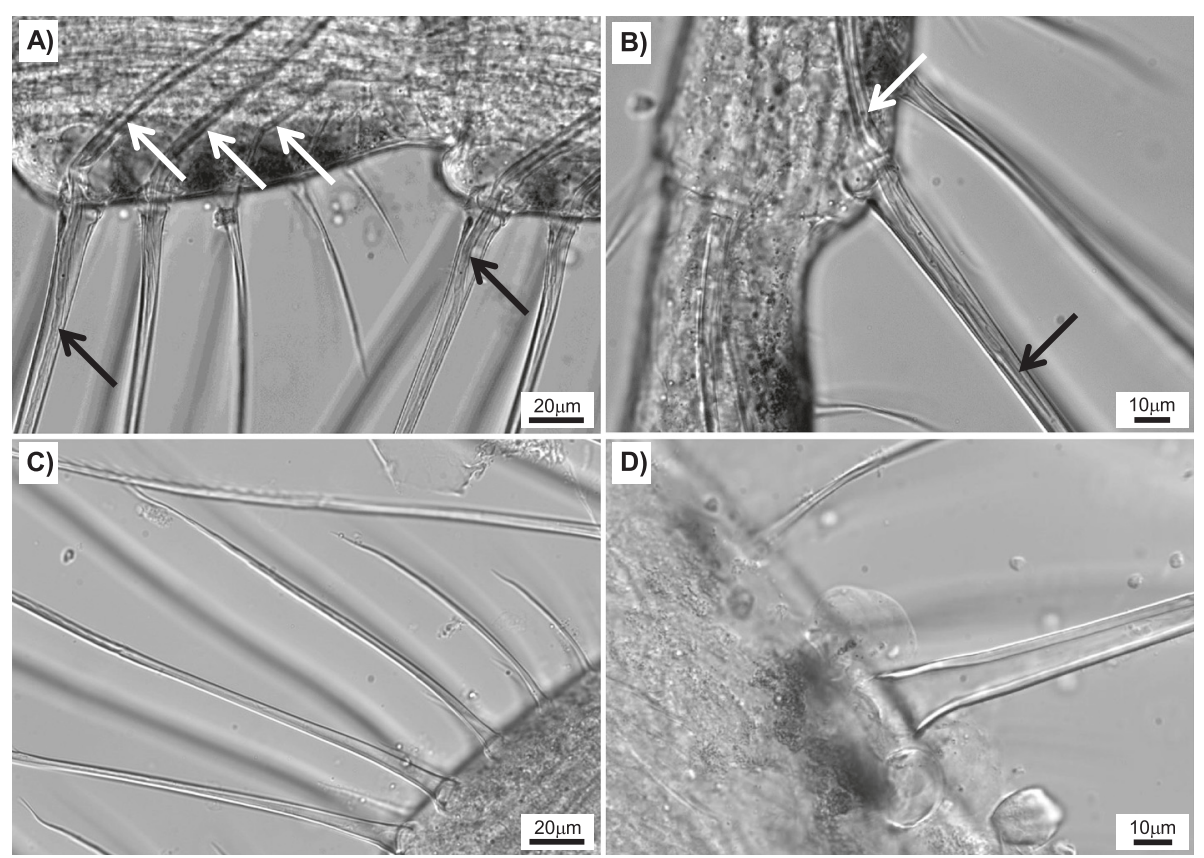

Fig. 2 Rami from adult barnacle A. amphitrite highlighting the setae in pre- and post-molt stages. a-b) Images of several setae from barnacles collected in pre-molt (proecdysis) stage. Black arrows indicate the presence of new setae development prior to molting, and white arrows indicate invaginations of the newly developing setae. c-d) Images of setae from barnacles collected in post-molt stages as indicated by the absence of new setae or invaginations and an expanded setal matrix

are secreted by cement glands located in the sub-mantle tissue $[2-5,7]$. A number of studies have identified five genes encoding cement proteins (termed cp19, сp20-1, cp20-2, cp52 and cp100 based on their molecular weight) from several barnacles including M. rosa, A. amphitrite and $T$. j. formosana and these studies also demonstrated most were abundantly expressed in the main body of the barnacle $[15,16]$. In this study, all of these cement protein transcripts were identified within the sub-mantle tissue (Table 2). Additionally, a novel paralogue of cp100k, named Aacp114k (A. amphitrite cement protein, M.W. 114kD), was also identified. This protein shares $58 \%$ homology with the amino acid sequence of the previously identified cp100k in A. amphitrite (accession number: AGS19349).

Table 1 Summary of A. amphitrite transcriptome

\begin{tabular}{ll}
\hline Total reads & $149,850,897$ \\
\hline Average length of each read (bp) & 90 \\
Total assembled sequence size (bp) & $114,232,646$ \\
GC content (\%) & 53.24 \\
Contig number & 163,929 \\
Contig mean length (bp) & 697 \\
Contig N50 (bp) & 1202 \\
Predicted transcripts & 160,266 \\
Transcripts annotated by SwissPro & 37,378 \\
Transcripts with GO term & 7045 \\
\hline
\end{tabular}

See Additional file 3 for sequence comparison and phylogeny analysis compared to other $100 \mathrm{k}$ homologues in $A$. amphitrite, M. rosa and T. j. formosana. To confirm the accuracy of transcriptome assembly of the Aacp114k gene, the full length cDNA $(3 \mathrm{~Kb})$ of this gene was amplified from the sub-mantle RNA with RT-PCR, cloned into the pET22b vector and sequenced. All but six nucleotides from the cloned fragment were identical to the assembled sequence (data not shown), indicating that Aacp114k gene is unique and was indeed present and expressed in the submantle of $A$. amphitrite. Sequence discrepancy between the Illumina sequencing and Sanger sequencing indicate heterogeneity within the samples collected for this study.

The transcriptomic data show that cement protein gene expression levels in the sub-mantle tissue did not have significant differences between pre- and post-molt stages, despite significant differences in the expression levels relative to one another (Fig. 3). These data suggest

Table 2 Comparison of cement proteins in A. amphitrite

\begin{tabular}{lllll}
\hline Protein ID & Length (aa) & pl & MW (kD) & GenBank Accession Number \\
\hline Aacp114k & 1000 & 10.02 & 114.2 & KP863707 (this study) \\
Aacp100k & 1156 & 10.19 & 129.5 & AGS19349 \\
Aacp52k & 629 & 10.47 & 73 & KP863709 (this study) \\
Aacp20k-1 & 113 & 5.26 & 12.9 & AFX74689 \\
Aacp20k-2 & 136 & 8.91 & 16 & AFX74690 \\
Aacp19k & 629 & 9.67 & 20.2 & KP863708 (this study) \\
\hline
\end{tabular}




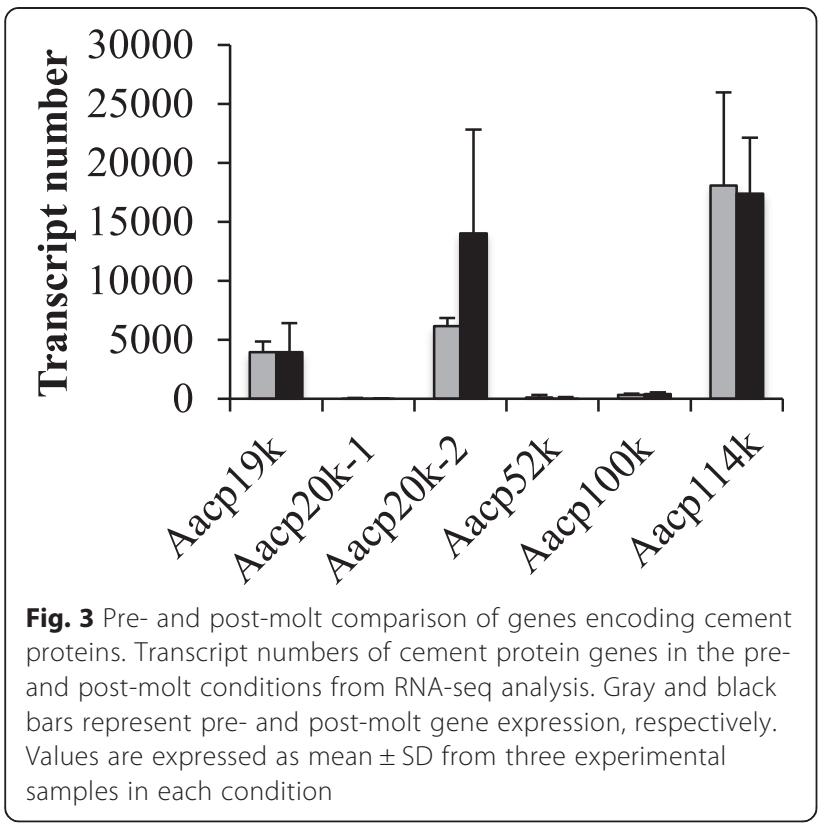

that expression of genes encoding cement proteins identified in the sub-mantle were independent of molting. Statistical analysis of a perceived difference in the preand post-molt transcript number of Aacp20k-2 showed the difference between these two populations is not significant. In terms of the general expression level of cement protein genes, Aacp19k, Aacp20k-2 and Aacp114k were expressed significantly higher than the other three cement protein genes based on transcript counts. It is noteworthy that the Aacp20k-1 and Aacp20-2 genes showed opposite expression patterns: Aacp20k-1 exhibited negligible expression, whereas Aacp $20 k-2$ was highly expressed in the sub-mantle tissue. Unlike the report by Lin et al. that the $c p 52 k$ gene was abundant in the basis of $T$. j. formosana [16], the expression level of Aacp52k in the sub-mantle tissue of A. amphitrite was relatively low (Fig. 3).

\section{Cement protein gene expression: main body versus sub- mantle tissue}

Next, the expression level of cement protein genes was compared on the basis of tissue, examining main body versus the sub-mantle tissue of adult $A$. amphitrite samples. mRNA was isolated from the main body and the transcript levels of the cement protein genes measured with qRT-PCR using the cytochrome b gene $(c y b)$ as an internal control. In general, the gene expression levels of cement protein genes in the main body were very low as detected by RT-PCR. This accentuates Fig. 4 , which is a semi-log plot of the relative fold change in the gene expression level of cement proteins in the sub-mantle tissue compared to the main body. Of the cement protein genes examined, all except Aacp20k-1 showed varying degrees of increased expression in sub-mantle tissue compared to the main body. The gene for Aacp20-1 was negligibly expressed in sub-mantle tissue and not expressed in the main body. Mass spectrometry was performed on submantle tissue samples processed at the same time as the mRNA collection with the intent to separate the proteinaceous content and target identification of cement proteins. No cement proteins were identified using this technique, though an overwhelming amount of housekeeping and scaffold proteins identified could have masked their presence.

\section{Secretion analysis}

In addition to examining cement protein gene expression levels, material secreted from barnacles at the substrate interface was analyzed using mass spectrometry. There is not a standard method to collect barnacle secretions, so different approaches were employed to identify the presence of cement proteins and attempt to correlate their presence in the sub-mantle tissue and the barnacle/substrate interface. See Methods for detailed explanation of the coverslip, medallion, mortar, and bead collection techniques.

In all secretion samples, the only cement proteins detected with MS analysis were the higher molecular weight Aacp100k and the newly identified Aacp114k (Table 3). Aacp114k was clearly present in the inverted coverslip, medallion, and microsphere samples. Two instances of Aacp114k were identified in the mortar samples. Interestingly, the presence of Aacp100k was confirmed in the medallion and microsphere samples, but not in either the coverslip or the mortar samples.

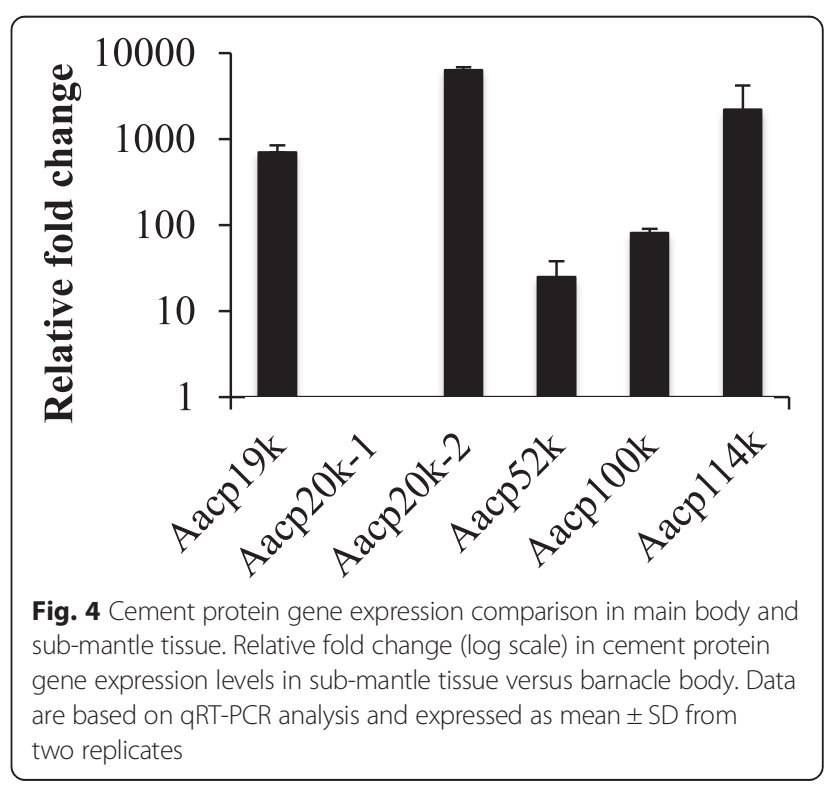


Table 3 Number of unique peptides identified for cp100k

\begin{tabular}{lllll}
\hline Protein & Coverslip & Medallion & Mortar & Bead \\
\hline Aacp114k & $12^{\text {a }}$ & 10 & 2 & 15 \\
Aacp100k & 0 & 6 & 0 & 5
\end{tabular}

${ }^{a}$ Peptide and protein identifications were accepted if they could be established at $>70 \%$ and $90 \%$ probability, respectively. Protein identifications also had to contain at least 2 identified peptides (see Methods)

\section{Extended analysis of differential gene expression: Pre- and post-molt}

One objective of this study was to examine the gene expression levels of cement proteins in the sub-mantle tissue and identify cement proteins from barnacle secretions. However, the transcriptome data collected from the preand post-molt sub-mantle tissue samples allowed for a more general examination of differential gene expression. The edgeR analysis package [20] revealed that of all predicted transcripts discovered from the transcriptome, 135 were differentially expressed between pre- and post-molt stages (false discovery rate $(\mathrm{FDR})<0.1$ ). A volcano plot representing highly expressed transcripts in the pre- and post-molt samples is shown in Fig. 5. Among these, 111 were highly expressed in pre-molt samples and only 24 transcripts in post-molt samples. These results indicate that barnacle molting is regulated by a limited number of genes with significantly more involved in preparing for and initiating molting.

To confirm the RNA-seq result, 11 transcripts were randomly selected from the differentially expressed transcripts and subjected to real time RT-PCR analysis. (See Additional file 4 for primer sequences and known gene functions). The expression changes between pre- and post-molt were indeed correlated to the RNA-seq data. Annotated transcripts that were differentially expressed in pre- and post-molt

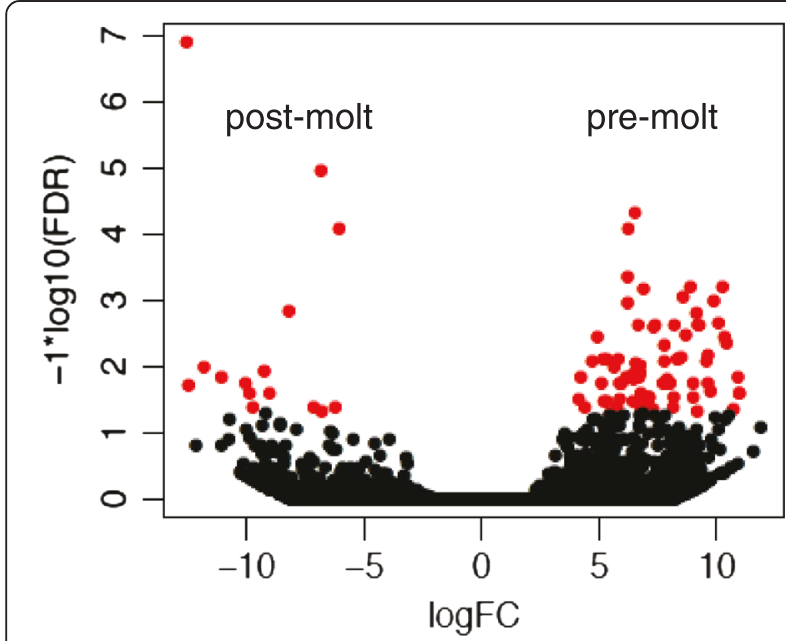

Fig. 5 Volcano plot of differential gene expression profile in pre- (right) and post-molt (left) conditions. Data points in red correspond to a false discovery rate $(F D R)<0.1$ samples are listed in Table 4. Several of the highly expressed transcripts in the pre-molt samples were found to encode cuticular proteins, metalloproteases, C-type lectins, and antioxidant enzymes (highlighted in gray in Table 4). Four of the transcripts encoding cuticle proteins and upregulated in pre-molt samples were found to contain the Rebers-Riddiford (RR) consensus motif $\left(\mathrm{Cx}_{8} \mathrm{Gx}_{6} \mathrm{Yx}\right.$ $\left.\mathrm{AxExGYx}_{7} \mathrm{Px}_{2} \mathrm{P}\right)$ [21], either in its complete form or in the partial form missing the two $\mathrm{C}$-terminal proline residues (Additional file 5).

Of the 135 differentially expressed transcripts in the pre- and post-molt samples (Additional file 6), proteins encoded by 27 of them (20\%) were identified in the secretion samples studied by proteomics, as highlighted in Table 4. Additional file 7 provides detailed information about protein identifications from these samples. Interestingly, one of the encoding genes highly expressed in pre-molt samples, comp97185_c0 (Additional file 6) shares $44 \%$ sequence homology to the settlement inducing protein complex (SIPC) of both A. amphitrite [22] and $M$. rosa [23]. Peptides of this protein were recovered and identified in all four barnacle secretion collections.

\section{Discussion}

In this study, we compare gene expression levels of preand post-molt barnacles while also examining the main body versus the sub-mantle tissue. The first comparison was enabled by tracking the shed exuvia of several barnacles and collecting sub-mantle tissue at time intervals preceding or following molt. The molt stage was confirmed by examining cirri anatomy via light microscopy and correlated with established stages of barnacle molting [17]. The two comparisons presented in this study have resulted in a thorough analysis of principal genes differentially expressed in pre- and post-molt stages and also a more complete picture of the abundance and presence of putative barnacle cement proteins involved in adhesion to the underlying surface of an adult barnacle.

The assembled transcriptome size ( 114 Mbp) in this study is more than four times greater than the number previously reported in A. amphitrite by Chen et al. [15]. In RNA-Seq analysis of differential gene expression in different conditions, it is very common that de novo assembling of eukaryotic transcriptome often reports fragmented transcripts of one gene or repeated contigs that only differ by a single-nucleotide polymorphism (SNP) or a base insertion or deletion (indel). Such expanded transcriptome size is usually evidence of isoforms of the same gene and artifacts such as sequencing errors, repeats, and variations in coverage and genetics within diploid individuals and pooled samples [24]. In our study, RNA of the pre- and post-molt samples was from six individuals and RNA of the whole bodies was collected from two pooled samples, each containing ten individual barnacles. 
Table 4 Differentially expressed transcripts in the pre- and post-molting conditions annotated from SwissPro database

\begin{tabular}{|c|c|c|c|}
\hline Gene ID & Function & E value $^{\mathrm{a}}$ & $\operatorname{LogFC}^{b}$ \\
\hline \multicolumn{4}{|c|}{ Up-regulation in pre-molt } \\
\hline comp53534_c0 & Lectin BRA-3 ${ }^{\mathrm{c}}$ & $5.00 \mathrm{E}-11$ & 7.79 \\
\hline comp29212_c0 & Nattectin & $1.00 \mathrm{E}-09$ & 7.77 \\
\hline comp50021_c0 & Cuticle protein AM/CP1114 & $8.00 \mathrm{E}-08$ & 6.85 \\
\hline comp47643_c0 & Cuticle protein AM/CP1114 & $7.00 \mathrm{E}-11$ & 6.72 \\
\hline comp26034_c1 & Larval cuticle protein LCP-14 & $2.00 \mathrm{E}-12$ & 6.52 \\
\hline comp41002_c0 & Endocuticle structural glycoprotein $\mathrm{SgAbd}-2$ & $1.00 \mathrm{E}-08$ & 6.43 \\
\hline comp26034_c0 & Larval cuticle protein LCP-14 & $8.00 \mathrm{E}-13$ & 6.21 \\
\hline comp44031_c1 & Zinc metalloproteinase nas- $15^{\mathrm{d}}$ & 1.00E-07 & 7.86 \\
\hline comp28040_c0 & Zinc metalloproteinase nas- 13 & $6.00 \mathrm{E}-54$ & 7.05 \\
\hline comp24855_c0 & Blastula protease 10 & $1.00 \mathrm{E}-61$ & 5.86 \\
\hline comp50104_c0 & Thioredoxin domain-containing protein 5 & $3.00 \mathrm{E}-105$ & 10.89 \\
\hline comp30314_c0 & Peroxiredoxin- 6 & $2.00 \mathrm{E}-82$ & 7.00 \\
\hline comp44396_c2 & Guanine nucleotide-binding protein subunit gamma-e & $1.00 \mathrm{E}-27$ & 8.57 \\
\hline comp27073_c0 & Guanine nucleotide-binding protein subunit gamma-e & $8.00 \mathrm{E}-29$ & 7.06 \\
\hline comp25306_c0 & Protein mab-21-like & $\mathbf{0}$ & 5.78 \\
\hline comp38605_c0 & Fukutin & $3.00 \mathrm{E}-36$ & 6.77 \\
\hline comp43913_c2 & Tetraspanin-9 & $2.00 \mathrm{E}-28$ & 6.74 \\
\hline comp40054_c0 & Apolipoprotein D & $1.00 \mathrm{E}-29$ & 6.54 \\
\hline comp35700_c0 & F-box/LRR-repeat protein 20 & $6.00 \mathrm{E}-07$ & 10.95 \\
\hline comp51629_c0 & Enhancer of rudimentary homolog & $1.00 \mathrm{E}-55$ & 10.95 \\
\hline comp57880_c0 & Probable urea active transporter 1 & $1.00 \mathrm{E}-68$ & 10.69 \\
\hline comp97185_c0 & Murinoglobulin-1 & $1.00 \mathrm{E}-56$ & 10.07 \\
\hline comp30442_c0 & Tubulin alpha-2 chain & $2.00 \mathrm{E}-47$ & 9.15 \\
\hline comp57879_c0 & Collagen-like protein 2 & $1.00 \mathrm{E}-24$ & 6.86 \\
\hline comp68876_c0 & Somatostatin receptor type 2 & $4.00 \mathrm{E}-62$ & 6.70 \\
\hline comp77827_c0 & Cytoplasmic protein NCK2 & $3.00 \mathrm{E}-34$ & 6.70 \\
\hline comp52132_c0 & V-type proton ATPase subunit G & $3.00 \mathrm{E}-22$ & 5.87 \\
\hline comp57451_c0 & Neuroendocrine protein $7 \mathrm{~B} 2$ & $6.00 \mathrm{E}-14$ & 5.22 \\
\hline comp26066_c0 & Myosin regulatory light chain 2 & $6.00 \mathrm{E}-35$ & 4.90 \\
\hline comp50562_c0 & Cell death activator CIDE-A & $2.00 \mathrm{E}-08$ & 4.38 \\
\hline comp25311_c0 & Insulinoma-associated protein 1 & $2.00 \mathrm{E}-22$ & 4.33 \\
\hline comp27615_c1 & Low-density lipoprotein receptor-related protein 5 & 3.00E-07 & 3.54 \\
\hline \multicolumn{4}{|c|}{$\underline{\text { Up-regulation in post-molt }}$} \\
\hline comp43363_c1 & Sex comb on midleg-like protein 2 & $6.00 \mathrm{E}-20$ & -6.06 \\
\hline comp56413_c0 & Translocon-associated protein subunit alpha & $2.00 \mathrm{E}-53$ & -6.83 \\
\hline comp82294_c0 & Carbohydrate sulfotransferase 14 & 3.00E-37 & -7.13 \\
\hline comp56522_c0 & Trifunctional enzyme subunit beta, mitochondrial & $\mathbf{0}$ & -8.18 \\
\hline comp60528_c0 & Serine/threonine-protein kinase/endoribonuclease IRE1 & $1.00 \mathrm{E}-58$ & -9.20 \\
\hline comp30690_c0 & 39S ribosomal protein L36, mitochondrial & $2.00 \mathrm{E}-08$ & -9.73 \\
\hline comp48988_c0 & Tetraspanin-11 & $1.00 \mathrm{E}-13$ & -10.01 \\
\hline comp48323_c0 & $\begin{array}{l}\text { Biogenesis of lysosome-related organelles complex } 1 \\
\text { subunit } 1\end{array}$ & $1.00 \mathrm{E}-38$ & -12.53 \\
\hline
\end{tabular}

${ }^{a} E$ value represents the transcript has the best hit in Swiss-Pro database; ${ }^{b}$ transcript fold change (FC) in log 10 between pre-molt and post-molt samples; ${ }^{c}$ items shaded in gray potentially linked to a pre-molt condition and most are discussed in further detail in main text; ${ }^{d}$ genes in bold indicate that their encoded proteins were identified in secretion analysis using mass spectrometry 
The transcriptome generated from those eight samples resulted in many paths in the graph construction during the assembly process, effectively fragmenting the assembly which ultimately produced 163,929 assembled contigs. The main contribution to the larger transcriptome size might be heterogeneities within input samples, which was indicated by following evidence: (1) when sequence reads from the pre- and post-molt conditions were assembled separately, the contig numbers were greatly reduced to 73,973 and 70,840 , respectively, and the total transcriptome sizes were reduced to approximately $42 \mathrm{Mbp}$ (see Additional file 8). (2) Further clustering these individual assemblies using a homology approach (CD-HIT, $95 \%$ homology) resulted in an overall reduced assembly of approximately $54.8 \mathrm{Mbp}$ in 95,873 contig clusters (35\% reduction from combined). Clustering the individual assemblies results in ca. $60 \mathrm{k}$ contig clusters in each condition, which might be closer to the expected gene number of the barnacle. The fact that the contig sequences from the pre- and post-molting samples do not cluster to a greater degree at $95 \%$ suggested that variation (splicing, SNP, sequencing error) played a greater role in the transcriptome assembly. (3) Finding a six nucleotide difference between the assembled and the cloned Aacp114 gene sequences (data not shown) also indicated the heterogeneity phenomenon present within individuals. Further inspecting the reads mapping to the Aacp114k gene, we observed many differences between the consensus sequences not shared across individual samples (data not shown).

The Illumina sequencing approach employed in the current study produced sequence coverage at $\sim 114 \mathrm{x}$, which is an order of magnitude higher than $8.6 \mathrm{x}$ coverage using the 454 method reported by Chen et al. [15]. Higher depth of sequencing would reveal more real alternative splicing transcripts and splicing variants, which contribute to greater numbers of assembled sequences and contigs. On the other hand, higher coverage may also amplify issues with genomic contamination, partially spliced products, and other artifacts of the method. In this study, we were only interested in genes changing within the conditions queried, negating many of these issues in the final differential analysis. As such, reducing the putative transcript/gene (cluster) tally was not necessary. Here, only about $23 \%$ of the $\sim 160,000$ predicted transcripts had annotated functions based on available database sequences, meaning the vast majority are unidentified. This trend was consistent even among the differentially expressed proteins in the pre- and post-molt tissue samples, indicating the need for a much larger effort of creating a fully annotated barnacle genome.

The main purpose of targeting the sub-mantle tissue for temporal comparative analysis is that, anatomically, this region is where cement-related tissue of adult barnacles resides. While it was straightforward to separate main body from sub-mantle tissue with little cross-contamination, collection of only cement gland tissue within the sub-mantle cavity proved more challenging. Ovarian tissue, identified by its distinct color and texture, was often intimately intertwined with the surrounding tissue, which included the cement glands $[25,26]$. During sample collection, care was taken to remove the vast majority of ovarian tissue, though its complete removal was beyond the scope of this investigation given the limits of dissection. Therefore, potential contamination of a minimal amount of ovarian tissue in the sub-mantle samples is a possibility. Despite this, the aim was to collect as much of the non-ovarian sub-mantle tissue as possible in order to have an optimal sampling of material thought to contain cement precursor materials. Judging by the gene expression data comparison between sub-mantle tissues and the main body, the sub-mantle tissues clearly demonstrates elevated expression of cement proteins and resulted in the identification of a new cementrelated protein.

In regard to temporal expression of cement protein genes, there have been previous claims of differential cement protein gene expression as a function of barnacle molting $[9,13]$, however, these are unsubstantiated and cite unpublished work. In the current study, several barnacle samples with regular molt cycles were chosen in either a pre- or post-molt state accompanied by collection of cirri for molt cycle confirmation based on established criteria [17]. For the detected cement protein genes (Fig. 3), there was no significant difference in the pre- and post-molt gene expression levels despite that fact that several other genes were found to be differentially expressed (Table 4). It may be possible to increase the resolution of molt-dependent gene expression using qRT-PCR according to eight (sub-)stages described by Davis et al. [17]. However, differential gene expression was intentionally limited to pre-molt and post-molt due to the considerable number of other parameters that, collectively, are difficult to control and monitor. These include barnacle size, age, and season, time variability within each molt stage and transcript heterogeneity. Despite these variables, two phenotypes were observed in the present study and were consistent among themselves.

The presence of cement proteins Aacp20-1 and -2 has been reported previously and were shown to localize and express in different types of secretory cells in the cyprid cement gland [27]. In adult barnacles, $\mathrm{He}$ et al. reported that protein Aacp20k-1 was present in soft tissue, whereas protein Aacp20k-2 was dominant in the basal shell of adult barnacles, which agrees with our gene expression results (Fig. 4). Interestingly, Aacp20k-1 is the only cement protein with a low $p I$ of $\sim 5$ (whereas the $p I$ values of all other cement proteins are $\sim 9$ or greater, see Table 2) and its gene expression was detected at very low levels in the sub-mantle tissue and not at all in the body. 
It is possible that transcripts of Aacp20k-1 are not stable and were degraded, making it difficult to assess if these results are coincident. Nevertheless, the questions of how and why this transcript is regulated are of interest.

We report high levels of gene expression of a novel paralogue cp100k protein termed Aacp114k. Irrespective of the pre- or post-molt stage, this newly identified protein had the highest gene expression compared to all other putative cement proteins located in the sub-mantle tissue based on transcript numbers (Fig. 3). These results and the relative change in expression level in the sub-mantle tissue versus body (Fig. 4) suggest that this protein is localized in sub-mantle tissue. Proteomic analysis confirms this protein is found in material secreted by the barnacle to a greater extent than the Aacp100k paralogue, as observed in coverslip, medallion, microsphere and mortar samples (Table 3). Based upon our gene expression and mass spectrometry results, we suggest the Aacp114k paralogue identified in the current study is a prominent protein component of barnacle cement in A. amphitrite. Interestingly, phylogenetic analysis of the various cp100 homologues show a closer relation between the cp100 homologue in A. amphitrite first identified by Chen et al. [15] and in T. j. formosana [16] than between the two paralogues found in A. amphitrite (Additional file 3).

A previous report on M. rosa claimed cp52k, cp68k, and $\mathrm{cp} 100 \mathrm{k}$ as being the major protein components of barnacle cement [7]. However, we were not able to identify a cp68k-related gene from the transcriptome in A. amphitrite mainly because the cp68k sequence is unavailable in public domains (such as Genbank, SwissPro) despite references to it having been identified and its sequence $[9,13]$. Using N-terminal sequences of eight cyanogen bromide (CB) peptides determined from the insolubilized cement fraction of $M$. rosa [8] as queries, we found that only five of those peptides were homologous to either Aacp52K or Aacp100K in our transcriptome database. Therefore, more studies are required to verify whether cp68k exists as single protein in A. amphitrite and, if so, whether the expression level is differentiated throughout molting.

In comparing the main body to the sub-mantle tissue using RT-PCR, cement protein genes were predominantly expressed in sub-mantle tissue, which is the expected location of barnacle cement precursor materials. Proteomic analysis of barnacle secretions collected using different techniques indicate that Aacp114k and Aacp100k are secreted by the animal at the barnacle/substrate interface. Of course, the inability to detect other putative cement proteins from the secreted materials does not necessarily mean they are not present. Two factors could contribute to this finding. First, the amount of secreted material is expected to be relatively low since the collection methods used in this study are targeted at newly secreted material over a limited time period with a maximum of 2 weeks and minimum of 1 day. (This is in comparison to collection of an entire, fully-formed cement plaque). In addition, MS analysis may lie outside the limits of detection or may indicate the proteins have been cross-linked prior to enzymatic digestion, escaping detection. Combined, these factors are likely to contribute to the limited detection of cement proteins in the various barnacle secretion collections. Nevertheless, the newly described variations to the collection methods of cement material over relatively short time frames using four different approaches (the coverslip, mortar, medallion, and bead techniques) allowed for proteomic comparison with sub-mantle tissue and offer a fresh means of analyzing recently secreted material and newly formed barnacle cement.

We expand upon the insights gained from cement protein (gene) detection and analysis to the more general findings of differential gene expression in the preand post-molt samples of the sub-mantle tissue. Most highly expressed genes were found in pre-molt samples and, of those identified, generally encoded proteins in four categories: cuticular proteins, metalloproteases, Ctype lectins, and antioxidants. These categories can be associated with molting, biomineralization, morphogenesis, and cell adhesion. Here, we provide a more indepth discussion of some of the highly expressed protein genes identified in the sub-mantle tissue of pre-molt barnacle samples.

The increased expression of cuticular protein genes was not unexpected since molting requires significant production of cuticular material and tissue scaffolding to replace the soon-to-be-shed exuvia. Several cuticlerelated protein genes in the pre-molt samples were identified and four were found to have the chitinbinding Rebers-Riddiford consensus motif [21]. Multiple transcripts of RR-containing cuticle proteins were reported to be temporally and spatially expressed in the decapod crustacean Callinectes sapidus and involved in biomineralization [28]. More than 60 homologs of this type of cuticle protein gene were identified from the transcriptome data in this study, indicating a variety of functions at different growth stages or conditions. RR-containing cuticle protein genes highly expressed in the pre-molt sub-mantle tissue of barnacles strongly suggest an involvement with chitin and possibly a role in biominerialization, both of which have a role in barnacle growth [4].

Two genes encoding C-type lectins, BRA-3 and nattectin, were also found to be highly expressed in the pre-molt condition. C-type lectins usually bind carbohydrate structures in a $\mathrm{Ca}^{2+}$-dependent manner and are well-recognized immune response initiator proteins [29]. They have been found to participate in mineralization [30] and inhibit the growth of calcium carbonate crystals [31]. High expression of these two genes in the pre-molt condition suggests that 
they have significant roles in biomineralization during growth/molting and coordinating post-molt responses.

Coincident differential expression of genes encoding peroxiredoxin- 6 and thioredoxin domain-containing protein 5 in pre-molt samples suggests that the barnacle experiences oxidative stress during or following molting, since peroxiredoxin uses thioredoxin to recharge after reducing hydrogen peroxide $\left(\mathrm{H}_{2} \mathrm{O}_{2}\right)$ so as to restore its catalytic activity [32]. Antioxidant proteins like peroxiredoxin are often coupled with others (like thioredoxin) to limit damage of oxidative stress to host tissue [33].

Increased expression of genes encoding proteases (including zinc metalloproteinases) in the pre-molt stage points toward proteolytic activation of proteins, including contributors to barnacle cement, having an essential role for effective cement cross-linking and co-adhesion within the interface. Zinc metalloproteinases have a significant role in inflammation as enzymes that rework extracellular matrices and remodeling of structural material [34]. In addition, it has previously been suggested that barnacle cement cross-linking involves proteolytic activation of structural proteins in order to maximize the potential for bonding interactions with other proteins and with the surface [35].

A glycoprotein, settlement inducing protein complex (SIPC) has been reported as the species-specific cue to settlement of barnacles $[22,23]$ and expressed in the cuticle of adults [36]. It has been reported as a complex of three proteins $(98,88$ and $76 \mathrm{kDa}$ ) but retains some biological activity as separate subunits $[37,38]$. In the transcriptomic data, we found SIPC that is $100 \%$ identical to the previously reported one [22] and its gene expressed at similar levels in both pre- and post-molt conditions. Interestingly, we also found a homologous SIPC gene, comp97185_c0 (Additional file 6), highly expressed in the pre-molt condition and its encoded peptides were identified in all secretion samples analyzed with MS. This finding suggests that the barnacle may secrete a new and different type or combination of SIPC molecule with alternative (non-SIPC) ligands as a molting signal, and its function is worth further investigation.

\section{Conclusion}

This work advances the understanding of the complex process of barnacle molting/growth by defining the temporal and tissue distribution of various proteins, including those reported to be major components of barnacle cement. Our analysis suggests there is not differential expression of cement protein genes in pre- and post-molt barnacles and most appear to be highly expressed in the sub-mantle tissue compared to the main body. In addition, we identify a novel cement protein homologue, Aacp114k, with high gene expression levels in the sub-mantle tissue and confirmed its presence in secretions at the barnacle/ substrate interface. In the absence of a fully annotated genome, our transcriptomic analysis reveals highly expressed genes identified in pre-molt barnacle samples and paints a picture of extensive cuticular development, biominerialization, and proteolytic activity that may be associated with the precursor elements of barnacle cement. Our results also highlight the fact that the majority of differentially expressed genes in the pre- and post-molt stage are unidentified and potentially unique to barnacles.

The description of several new cement collection techniques opens opportunity to build a profile of the macromolecules present and active at the barnacle/substrate interface with the goal of elucidating the mechanism of the cementing process. Future directions include developing approaches to collect and profile pre-secreted material as well as establishing protocols to identify the location of various cement components prior to secretion. We note that in situ hybridization studies have been carried out in A. amphitrite cyprids [17] and offer great potential for identifying the tissue (or cell) specific expression of particular genes relevant to the current study. Given the increased complexity of the adult barnacle anatomy and the fact that all tissue is surrounded by an opaque calcified shell, there are challenges with in situ hybridization that are beyond the scope of the current work yet are a promising future direction.

Ultimately, the research goals are to identify the various precursor components of barnacle cement, understand the mechanism of delivery, and how the components interact at the substrate interface. A complete understanding of this process can lead to targeted strategies to mitigate barnacle adhesion as well as mimic its functionality in underwater environments.

\section{Methods}

\section{Barnacle husbandry}

$A$ amphitrite cyprids were settled and raised on silicone coated panels as previously described [39] until they were mature enough to be fed Artemia spp. nauplii. Samples were then shipped to the Naval Research Laboratory where they were maintained in an incubator at $23{ }^{\circ} \mathrm{C}$ with $12 \mathrm{~h}$ daylight cycles in $32 \mathrm{ppt}$ artificial seawater and fed Artemia spp. nauplii every other day. In addition, the water for barnacles was changed weekly during which the algal growth was removed. Barnacles were reattached from the silicone panels to alternative substrates for the experiments [40].

\section{Molt cycle analysis and cirri imaging}

A subset of over ten barnacles were reattached to glass slides, kept individually in separate containers to track the molt cycles over the course of several weeks (minimum of 
2 weeks). Molting was noted by the presence of the exuvia in an individual barnacle container and, depending on the age or size of the barnacles, occurred anywhere from every 3 to 7 days. Barnacles molting in a regular pattern were selected for this study. For pre- and post-molt comparison, three barnacles were sacrificed the day prior and three the day after a molt, for a total of six individual samples. The cirri were removed for light microscopy observation (see below). In other barnacles undergoing regular molt cycles, only the main body was collected for subsequent protein and mRNA analysis and the cirri were removed for light microscopy analysis.

Cirri were examined using differential interference contrast (DIC) light microscopy on a Nikon TE2000 inverted microscope to confirm the molting stage of each sample. Following the procedure of Davis et al. [17], setae from the upper portion of cirri (rami) were imaged under $20 x$ and $40 \times$ magnification. Several segments were imaged for consistency and structural features identifying the molt stage were noted. Davis et al. categorize four main stages, A through $\mathrm{D}$, of barnacle molting proceeding through a short time period following molting (stage A) to the period prior to molting (stage D). These main stages are discriminated further into eight sub-stages. For the purposes of this study we have generalized these stages to two main categories: i) pre-molt (proecdysis, stage D) and ii) post-molt (post- or interecdysis, stages B or C).

\section{Total RNA and protein collection}

Isolation of total RNA from whole body tissue without the sub-mantle tissue was performed in the following manner. First, the main body was removed from a barnacle shell that had been cracked open with sharp tweezers followed by the addition of TRIzol Reagent (Life Technologies Inc., Grand Island, NY) according to the manufacturer's protocol. The soft body tissues in TRIzol were vigorously vortexed and resuspended several times to break them apart. Chloroform was then added and mixed evenly by vortexing. The mixture was allowed to sit at room temperature for $2-3 \mathrm{~min}$ and centrifuged. Subsequently, the liquid phase was removed without disturbing the interphase precipitate and mixed with isopropanol to precipitate total RNA, followed by centrifugation and washing the pellet with $75 \%$ ethanol. The rest of liquid phase including the interphase precipitate was then subjected to DNA and protein isolation according to the manufacturer's protocol. The total RNA was further treated with DNAse I to get rid of DNA contaminants using on-column digestion (Qiagen Inc., Valencia, CA).

A similar procedure was used for isolating total RNA from sub-mantle tissue. The main body of the animal was removed as well as the underlying inner mantle and the sub-mantle tissue carefully collected with several gentle pipette suctions for processing. A schematic of the barnacle anatomy highlighting the main body and sub-mantle tissue is shown in Fig. 1. Ovarian tissue, which was clearly evident based on its color and texture with respect to surrounding tissue, was carefully removed with tweezers to minimize/ eliminate its inclusion for subsequent processing/analysis.

For all samples, isolated total RNA were examined by agarose gel electrophoresis. A quality check was performed using a Bioanalyzer (Agilent Technologies) and RNA samples were found to be of high quality with no DNA contamination.

\section{mRNA sequencing and data analysis}

Three separate samples of the sub-mantle tissue from the pre- and post-molting conditions and two pooled samples from the whole body (10 samples in each; all without the sub-mantle tissue) were collected for RNA sequencing (RNA-seq) experiments. Enrichment of poly(A) RNA, synthesis of cDNA and construction of cDNA libraries were processed using protocols provided by Illumina, Inc. (San Diego, CA). Libraries were sequenced on an Illumina HisSeq2000 Sequencer in 100 paired-end configuration. Following sequencing, data was trimmed for both adaptor and quality using a combination of EA-utils and Btrim $[41,42]$. Trimmed-paired reads were then de novo assembled using Trinity software using the default parameters found in the online protocol [18]. Assembled transcripts were also further clustered into putative gene clusters using CD-HIT-EST [43]. Annotation of transcripts was performed using the Transdecoder/Trinotate package [http:// www.vcru.wisc.edu/simonlab/bioinformatics/programs/ trinity/docs/annotation/Trinotate.html] (blast based annotation using Swissprot) with the default E-value as 1e-6. Read alignment and estimation of transcript abundance was performed using Bowtie2 [44] and RSEM [45] as described in the Trinity abundance estimation protocol. Transcripts differentially expressed between two conditions were identified by comparing absolute number of transcripts across biological replicates with $\mathrm{FDR}<0.1$ as the cutoff value using the EdgeR software package [20], again as described in the Trinity protocol. Raw sequence reads were deposited in Genbank as BioProject PRJNA271096.

\section{qRT-PCR}

The primers used for the quantitative real-time reverse transcription polymerase chain reaction (qRT-PCR) assays are listed in Additional file 4. The cytochrome b gene $(c y b)$ of $A$. amphitrite was chosen as an internal control. The qRT-PCR was conducted on an iCycler (BioRad Laboratories) using the iScript OneStep RT-PCR Kit with SYBR Green (BioRad Laboratories). qRT-PCR reaction mixtures consisted of $10 \mathrm{ng}$ of total RNA from each extracted sample, $200 \mathrm{nM}$ of primers and were subjected to the following cycling conditions: one cycle at $50{ }^{\circ} \mathrm{C}$ for $30 \mathrm{~min}$ and $95{ }^{\circ} \mathrm{C}$ for $15 \mathrm{~min}$, followed by 40 cycles of $94{ }^{\circ} \mathrm{C}$ 
for $15 \mathrm{~s}, 52{ }^{\circ} \mathrm{C}$ for $30 \mathrm{~s}$ and $72{ }^{\circ} \mathrm{C}$ for $30 \mathrm{~s}$. Triplicates for each RNA sample were collected for statistical analysis. The average cycle threshold $(\mathrm{Ct})$ value for each tested RNA sample was obtained and the gene expression level was then used for comparison among tissue samples. Relative quantities of transcript were determined using the $2^{-\Delta \Delta C t}$ formula. $\Delta \mathrm{Ct}$ is the difference in $\mathrm{Ct}$ of the gene of interest and $\mathrm{Ct}$ of the normalizer gene, and $\Delta \Delta \mathrm{Ct}$ is the difference in $\Delta \mathrm{Ct}$ from the sub-mantle sample and $\Delta \mathrm{Ct}$ from the body sample. Cytochrome b gene $(c y b)$ was used to normalize expression levels of genes of interest because its transcript was constant in all conditions in this study.

\section{Cloning and sequencing of Aacp114k encoding gene}

Total RNA isolated from sub-mantle tissues were reverse transcribed to cDNA according to the manufacturer's protocol (Life Technologies). The first strand cDNA was then used as a template along with the primers, 114KNcoIF (5'AAAAACCATGGGCATGCTGCGGCTCT CGCTAGC3') and 114KXhoIR (5'GGGGGCTCGAGGCACTTGAAGTAGTCGTAC3'), to amplify the Aacp114k transcript by conducting PCR. Resulting $3 \mathrm{~kb}$ DNA fragments were digested with $\mathrm{NcoI}$ and XhoI, followed by cloning into a pET22b vector. The cloned plasmids were propagated in E. coli Top10 in LB culture supplemented with ampicillin. The insert of isolated plasmid was sequenced using the Sanger sequencing method (Eurofins Genomics).

\section{Barnacle secretion collection}

There is not a standard procedure to collect barnacle cement and secretions, so to maximize the opportunity to identify potential cement proteins collection of barnacle secretions was carried out in three different ways to produce four different samples for subsequent analysis. From each collection method, the majority of protein was solubilized. Any insoluble fraction was minimal and remained on the respective surface. A description of each technique is provided below.

\section{Coverslip}

In the first, adult barnacles were gently removed from silicone substrates and all shell plates, including the base plate, were rinsed and cleaned with a cotton swab in deionized water. The barnacles were then inverted and settled onto a Plexiglas ${ }^{\oplus}$ platform engineered with circular openings, which allowed the apical portion of the organism to be partially submerged in sea water to allow for continuous feeding and growth during the cement collection process. A No. 2, $12 \mathrm{~mm}$ diameter borosilicate cover glass (Fisher Scientific \#22-293-232) was placed on top of the exposed base plate as a substrate to collect secreted material from the barnacle (see Additional file 9 for schematic of setup). After 24-48 h at room temperature, the cover glass substratum was gently removed using a dissecting needle. In order to maximize sample collection, the entire cover glass was placed into a $1.65 \mathrm{~mL}$ microfuge tube and crushed with a glass rod. Next, $100 \mu \mathrm{L} 1 \times$ Laemmli sample buffer was directly added to the sample and heated for three minutes at $95{ }^{\circ} \mathrm{C}$. Finally, $50 \mu \mathrm{L}$ of the solubilized sample was separated by SDS-PAGE (4-20\% TGX precast gel; BioRad) and used for further mass spectrometry analysis. These samples are referred to as "coverslip" samples.

\section{Mortar and medallions}

In the second, adult barnacles were transferred from silicone panels and settled on sodium aluminoborate $\left(\mathrm{Na}_{2} \mathrm{O} \cdot \mathrm{Al}_{2} \mathrm{O}_{3} \cdot 3 \mathrm{~B}_{2} \mathrm{O}_{3}\right)$ glass substrates, which form a hydrated reaction layer $(<25 \mu \mathrm{m}$ thick) in aqueous environments that is resistant to barnacle adhesion [46]. After 2 weeks, barnacle bodies and side plates were carefully removed, leaving the base of the barnacles attached to the substrates which were then cleaned with a cotton swab in deionized water to remove loosely bound organic matter (see Additional file 9). Base plates were then de-minerialized by immersing substrates in $0.1 \mathrm{M}$ ethylenediaminetetraacetic acid (EDTA) at room temperature for 48-72 h. The organic remnants of the base plates were collected and placed in $50 \mu \mathrm{L}$ of $0.1 \%(\mathrm{w} / \mathrm{v})$ sodium dodecyl sulfate (SDS) solution in deionized water for subsequent analysis; these are referred to as "mortar" samples. Likewise, barnacle "medallions," consisting of the cuticular layer and underlying barnacle secretions, were gently rinsed with deionized water then peeled off the aluminoborate glass substrates and placed in $50 \mu \mathrm{L}$ of the SDS solution. Next, $50 \mu \mathrm{L}$ of Laemmli sample buffer containing $300 \mathrm{mM}$ dithiothreitol (DTT) was added to both samples and the resulting suspensions were incubated for $15 \mathrm{~min}$ at $95^{\circ} \mathrm{C}$ to solubilize proteins in the samples. After centrifugation (9000 rpm for $1 \mathrm{~min}$ ), supernatants were separated by SDSPAGE for further analysis. This procedure resulted in the cuticle being pelleted to the bottom of the centrifuge tube.

\section{Bead}

In the third type of preparation, borosilicate glass microspheres $(<50 \mu \mathrm{m}$ in diameter) were placed in the bottom of dishes filled with ASW to form a bed of microspheres 2-3 $\mathrm{mm}$ in depth. Adult barnacles $(n=5)$ were then transferred from silicone panels onto the bed of microspheres. After $24 \mathrm{~h}$, barnacles were lifted out, and those with microspheres attached to their underside (three out of the five) were gently scraped to remove the majority of the microspheres without damaging the barnacles (see Additional file 9). The collected microspheres were placed in $50 \mu \mathrm{L}$ of an SDS solution, vortexed, and centrifuged at $9000 \mathrm{rpm}$ for $1 \mathrm{~min}$. The resulting supernatant was collected, mixed in a 1:1 ratio 
with Laemmli sample buffer, and then separated by SDS-PAGE for further analysis and referred to as "bead" samples.

\section{LC-MS/MS}

Individual bands from protein extracts of each sample separated on SDS-PAGE gels were excised and digested in gel by trypsin. Peptides were extracted by $2 \%$ formic acid in 50/50 acetonitrile/water, followed by $100 \%$ acetonitrile. Digests were analyzed by liquid chromatographymass spectrometry/mass spectrometry (LC-MS/MS) using Tempo-MDLC coupled to a QStar Elite mass spectrometer (AB Sciex, Foster City, CA). Tandem mass spectra were extracted by AB Sciex MS data convertor version 2 . Charge state deconvolution and deisotoping were not performed. All MS/MS samples were analyzed using Mascot (Matrix Science, London, UK; version 2.4.1) and X! Tandem (The GPM, thegpm.org; version CYCLONE (2010.12.01.1)). Mascot was set up to search the BALAM_adhesproteins_003 database (1492 entries) assuming the digestion enzyme trypsin. X! Tandem was set up to search a subset of the BALAM database also assuming trypsin. Mascot and X! Tandem were searched with a fragment ion mass tolerance of $0.80 \mathrm{Da}$ and a parent ion tolerance of $0.80 \mathrm{Da}$. Deamidation of asparagine and glutamine, oxidation of methionine, acetyl of the $\mathrm{N}$-terminus and carbamidomethyl of cysteine were specified in Mascot as variable modifications. Glu- > pyro-Glu of the N-terminus, ammonia-loss of the N-terminus, gln- > pyro-Glu of the N-terminus, deamidated of asparagine and glutamine, oxidation of methionine, acetyl of the $\mathrm{N}$-terminus and carbamidomethyl of cysteine were specified in X! Tandem as variable modifications. Scaffold (version Scaffold_4.2.1, Proteome Software Inc., Portland, OR) was used to validate MS/MS based peptide and protein identifications. Peptide identifications were accepted if they could be established at greater than $70 \%$ probability by the Peptide Prophet algorithm [47] with Scaffold delta-mass correction. Protein identifications were accepted if they could be established at greater than $90 \%$ probability and contained at least 2 identified peptides. Protein probabilities were assigned by the Protein Prophet algorithm [48]. Proteins that contained similar peptides and could not be differentiated based on MS/MS analysis alone were grouped to satisfy the principles of parsimony. Proteins sharing significant peptide evidence were grouped into clusters.

\section{Availability of supporting data}

The data sets supporting the results of this article are available in the Proteomics IDEntifications (PRIDE) repository, http://www.ebi.ac.uk/pride/archive/projects/PXD001982. Other supporting data are presented in Additional files 1, 2, $3,4,5,6,7,8$ and 9 and also found in the same repository.

\section{Additional files}

\begin{abstract}
Additional file 1: Plot summarizing the contig length distribution. (PDF $92 \mathrm{~kb}$ )

Additional file 2: Graph with the abundance profiles of functional groups from the combined pre- and post-molt data sets. (PDF $73 \mathrm{~kb}$ ) Additional file 3: Sequence comparison and phylogeny analysis of Aacp $114 \mathrm{k}$ compared to other $100 \mathrm{k}$ homologues in $A$. amphitrite, $M$. rosa and $T$. j. formosana. (PDF $213 \mathrm{~kb}$ )
\end{abstract}

Additional file 4: RT-PCR primer sequences of 11 transcripts randomly selected from the differentially expressed transcripts and their gene functions. Primer sequences of the cement proteins and cytochrome $b$ are also included. (PDF $17 \mathrm{~kb}$ )

Additional file 5: ClustalX alignment of deduced cuticle protein sequences which encoding genes were highly expressed in the pre-molt stage. Rebers-Riddiford (RR) consensus sequence is highlighted. (PDF 183 kb)

Additional file 6: Table of the 135 differentially expressed transcripts in the pre- and post-molt samples. (XLSX $31 \mathrm{~kb}$ )

Additional file 7: Detailed information about protein identifications from the various secreted samples. (XLSX $117 \mathrm{~kb}$ )

Additional file 8: Comparison of sequence assemblies in the pre- and post-molt samples. (PDF $6 \mathrm{~kb}$ )

Additional file 9: Schematics and experimental conditions of the barnacle secretion collection methods. (PDF 537 kb)

\section{Competing interests}

The authors declare they have no competing interests.

\section{Authors' contributions}

ZW: RNA-seq and RT-PCR data analysis, manuscript preparation; DHL: LC-MS/ MS data collection, analysis, manuscript preparation; JL: tissue collection, RT-PCR analysis, Aacp114k cloning and sequencing, conceived experiments; manuscript preparation; RES: RNA-seq data collection, analysis, manuscript preparation; KPF, SN: cement sample collection, processing, manuscript preparation; AM: RT-PCR collection and analysis; TEB, SEH: barnacle husbandry, tissue dissection, sample collection, manuscript preparation; KJW: supervised experiments, manuscript preparation; CMS: conceived and supervised experiments, manuscript preparation. All authors read, edited, and approved the final manuscript.

Authors' information

Work by Anahita Mostaghim, Tara Essock-Burns and Sarah E. Haynes performed while summer interns at the Naval Research Laboratory.

\section{Acknowledgements}

We gratefully acknowledge Prof. Dan Rittschof and Ms. Beatriz Orihuela from Duke University Marine Lab for supplying the juvenile and adult barnacle samples. T.E.B. and S.E.H were supported through the Naval Research Enterprise Internship Program and A.M. through an NRL summer internship. Funding for this work was provided by Naval Research Laboratory base funding and the Office of Naval Research.

\section{Author details}

${ }^{1}$ Center for Bio/Molecular Science and Engineering, Naval Research Laboratory, Washington, DC 20375, USA. Virginia Bioinformatics Institute, 1015 Life Science Circle, Blacksburg, VA 24061, USA. ${ }^{3}$ Chemistry Division, Naval Research Laboratory, Washington, DC 20375, USA. ${ }^{4}$ Present address: Eastern Virginia Medical School, 700 West Olney Road, Norfolk, VA 23507, USA. ${ }^{5}$ Present address: Duke University Marine Laboratory, 135 Duke Marine Lab Rd. Beaufort, North Carolina 28516, USA. ${ }^{6}$ Present address: Department of Chemistry, University of Michigan, 930 N. University Avenue, Ann Arbor, Ml 48109, USA.

Received: 18 August 2015 Accepted: 8 October 2015

Published online: 24 October 2015 


\section{References}

1. Walker G. Adhesion of Barnacles. J Adhesion. 1981;12:51-8.

2. Saroyan JR, Lindner E, Dooley CA. Repair and Reattachment in Balanidae as Related to Their Cementing Mechanism. Biol Bull. 1970;139:333-50.

3. Burden DK, Barlow DE, Spillmann CM, Orihuela B, Rittschof D, Everett RK, et al. Barnacle Balanus amphitrite Adheres by a Stepwise Cementing Process. Langmuir. 2012;28:13364-72.

4. Burden DK, Spillmann CM, Everett RK, Barlow DE, Orihuela B, Deschamps JR, et al. Growth and development of the barnacle Amphibalanus amphitrite: time and spatially resolved structure and chemistry of the base plate. Biofouling. 2014;30:799-812.

5. Walker G. Biochemical Composition of Cement of 2 Barnacle Species, Balanus-Hameri and Balanus-Crenatus. J Mar Biol Assoc UK. 1972;52:429-35.

6. Naldrett MJ. The Importance of Sulfur Cross-Links and Hydrophobic Interactions in the Polymerization of Barnacle Cement. J Mar Biol Assoc UK 1993;73:689-702.

7. Kamino K, Inoue K, Maruyama T, Takamatsu N, Harayama S, Shizuri Y. Barnacle cement proteins - Importance of disulfide bonds in their insolubility. J Biol Chem. 2000:275:27360-5.

8. Kamino K, Odo S, Maruyama T. Cement proteins of the acorn barnacle Megabalanus rosa. Biol Bull. 1996;190:403-9.

9. Kamino K. Underwater adhesive of marine organisms as the vital link between biological science and material science. Mar Biotechnol. 2008;10:111-21.

10. Jonker JL, von Byern J, Flammang P, Klepal W, Power AM. Unusual adhesive production system in the barnacle Lepas anatifera: An ultrastructural and histochemical investigation. J Morphol. 2012;273:1377-91.

11. Jonker JL, Abram F, Pires E, Coelho AV, Grunwald I, Power AM. Adhesive Proteins of Stalked and Acorn Barnacles Display Homology with Low Sequence Similarities. Plos One. 2014;9:e108902.

12. Nakano M, Kamino K. Amyloid-like Conformation and Interaction for the Self-Assembly in Barnacle Underwater Cement. Biochem. 2015;54:826-35.

13. Kamino K. Barnacle Underwater Cement. In: Smith AM, Callow JA, editors. Biological Adhesives. Berlin: Springer; 2006. p. 145-66.

14. De Gregoris TB, Borra M, Biffali E, Bekel T, Burgess JG, Kirby RR, Clare AS. Construction of an adult barnacle (Balanus amphitrite) cDNA library and selection of reference genes for quantitative RT-PCR studies. BMC Mol Biol. 2009; 10:doi:10.1186/1471-2199-1110-1162.

15. Chen ZF, Matsumura K, Wang H, Arellano SM, Yan XC, Alam I, et al. Toward an Understanding of the Molecular Mechanisms of Barnacle Larval Settlement: A Comparative Transcriptomic Approach. Plos One. 2011;6:e22913

16. Lin HC, Wong YH, Tsang LM, Chu KH, Qian PY, Chan BKK. First study on gene expression of cement proteins and potential adhesion-related genes of a membranous-based barnacle as revealed from Next-Generation Sequencing technology. Biofouling. 2014;30:169-81.

17. Davis CW, Fyhn UEH, Fyhn HJ. Intermolt Cycle of Cirripeds - Criteria for Its Stages and Its Duration in Balanus-Amphitrite. Biol Bull. 1973;145:310-22.

18. Grabherr MG, Haas BJ, Yassour M, Levin JZ, Thompson DA, Amit I, et al. Full-length transcriptome assembly from RNA-Seq data without a reference genome. Nat Biotechnol. 2011;29:644-52.

19. Haas BJ, Papanicolaou A, Yassour M, Grabherr M, Blood PD, Bowden J, et al De novo transcript sequence reconstruction from RNA-seq using the Trinity platform for reference generation and analysis. Nat Protoc. 2013;8:1494-512.

20. Robinson MD, McCarthy DJ, Smyth GK. edgeR: a Bioconductor package for differential expression analysis of digital gene expression data. Bioinformatics. 2010;26:139-40.

21. Rebers JE, Riddiford LM. Structure and Expression of a Manduca-Sexta Larval Cuticle Gene Homologous to Drosophila Cuticle Genes. J Mol Biol. 1988:203:411-23.

22. Dreanno C, Matsumura K, Dohmae N, Takio K, Hirota H, Kirby RR, et al. An alpha(2)-macroglobulin-like protein is the cue to gregarious settlement of the barnacle Balanus amphitrite. P Natl Acad Sci USA. 2006;103:14396-401.

23. Yorisue T, Matsumura K, Hirota H, Dohmae N, Kojima S. Possible molecular mechanisms of species recognition by barnacle larvae inferred from multispecific sequencing analysis of proteinaceous settlement-inducing pheromone. Biofouling. 2012;28:605-11.

24. Davidson NM, Oshlack A. Corset: enabling differential gene expression analysis for de novo assembled transcriptomes. Genome Biol. 2014;15:410.

25. Lacombe D. A Comparative Study of Cement Glands in Some Balanid Barnacles (Cirripedia-Balanidae). Biol Bull. 1970;139:164-79.
26. Walker G. Histochemistry and Ultrastructure of Cement Apparatus of 3 Adult Sessile Barnacles, Elminius-Modestus, Balanus-Balanoides and BalanusHameri. Mar Biol. 1970;7:239-48.

27. He LS, Zhang G, Qian PY. Characterization of Two 20 kDa-Cement Protein (cp20k) Homologues in Amphibalanus amphitrite. Plos One. 2013;8:e64130

28. Wynn A, Shafer TH. Four differentially expressed cDNAs in Callinectes sapidus containing the Rebers-Riddiford consensus sequence. Comp Biochem Phys B. 2005:141:294-306.

29. Robinson MJ, Sancho D, Slack EC, LeibundGut-Landmann S, Sousa CRE. Myeloid C-type lectins in innate immunity. Nat Immunol. 2006;7:1258-65.

30. Kamiya $H$, Jimbo M, Yako H, Muramoto K, Nakamura O, Kado R, et al. Participation of the C-type hemolymph lectin in mineralization of the acorn barnacle Megabalanus rosa. Mar Biol. 2002:140:1235-40.

31. Muramoto K, Yako H, Murakami K, Odo S, Kamiya H. Inhibition of the Growth of Calcium-Carbonate Crystals by Multiple Lectins in the Celomic Fluid of the Acorn Barnacle Megabalanus-Rosa. Comp Biochem Phys B. 1994:107:401-9.

32. Rhee SG, Kang SW, Chang TS, Jeong W, Kim K. Peroxiredoxin, a novel family of peroxidases. IUBMB Life. 2001;52:35-41.

33. Robinson MW, Hutchinson AT, Dalton JP, Donnelly S. Peroxiredoxin: a central player in immune modulation. Parasite Immunol. 2010;32:305-13.

34. Parks WC, Wilson CL, Lopez-Boado YS. Matrix metalloproteinases as modulators of inflammation and innate immunity. Nat Rev Immunol. 2004:4:617-29

35. Dickinson GH, Vega IE, Wahl KJ, Orihuela B, Beyley V, Rodriguez EN, et al. Barnacle cement: a polymerization model based on evolutionary concepts. J Exp Biol. 2009;212:3499-510

36. Dreanno C, Kirby RR, Clare AS. Locating the barnacle settlement pheromone: spatial and ontogenetic expression of the settlement-inducing protein complex of Balanus amphitrite. P R Soc B. 2006;273:2721-8.

37. Matsumura K, Nagano M, Fusetani N. Purification of a larval settlement-inducing protein complex (SIPC) of the barnacle, Balanus amphitrite. J Exp Zool. 1998:281:12-20.

38. Clare AS, Matsumura K. Nature and perception of barnacle settlement pheromones. Biofouling. 2000;15:57-71.

39. Holm ER, Orihuela B, Kavanagh CJ, Rittschof D. Variation among families for characteristics of the adhesive plaque in the barnacle Balanus amphitrite. Biofouling. 2005;21:121-6.

40. Rittschof D, Orihuela B, Stafslien S, Daniels J, Christianson D, Chisholm B, et al. Barnacle reattachment: a tool for studying barnacle adhesion. Biofouling. 2008;24:1-9.

41. Aronesty E. EA-utils: Command-line tools for processing biological sequencing data, version 1.1.2-537. [http://code.google.com/p/ea-utils]

42. Kong Y. Btrim: A fast, lightweight adapter and quality trimming program for next-generation sequencing technologies. Genomics. 2011;98:152-3.

43. Li WZ, Godzik A. Cd-hit: a fast program for clustering and comparing large sets of protein or nucleotide sequences. Bioinformatics. 2006;22:1658-9.

44. Langmead B, Salzberg SL. Fast gapped-read alignment with Bowtie 2. Nat Methods. 2012;9:357-9.

45. Li B, Dewey CN. RSEM: accurate transcript quantification from RNA-Seq data with or without a reference genome. BMC Bioinformatics. 2011; 12:doi 10.1186/1471-2105-1112-1323.

46. Fears K. Surface-active glasses as regenerative anti-fouling materials. 2014, USPTO\# 14/504,657.

47. Keller A, Nesvizhskii Al, Kolker E, Aebersold R. Empirical statistical model to estimate the accuracy of peptide identifications made by MS/MS and database search. Anal Chem. 2002:74:5383-92.

48. Nesvizhskii Al, Keller A, Kolker E, Aebersold R. A statistical model for identifying proteins by tandem mass spectrometry. Anal Chem. 2003;75:4646-58. 